\title{
ANTROPOLOGÍA DE LA ALIMENTACIÓN. LA COMIDA Y EL COMER
}

\author{
Marcos Yauri Montero
}

\section{RESUMEN}

Este artículo es un acercamiento al rango que las plantas alimenticias peruanas poseen en el imaginario cultural. Asimismo a los significados de la comida y del comer dentro de la escala social, cultural y económica de la realidad.

PalABRAS CLAVE: Plantas alimenticias peruanas, comida, comer, rango, imaginario cultural.

\section{THE MEAL'S ANTHROPOLOGY. MEAL AND EAT}

\section{ABSTRACT}

This article, is an approach to the level of importance that alimentary Peruvian plants have in the imaginary culture. As well as, to the meanings of foods inside of the social, cultural, and economical level of reality.

KEYWORDS: Alimentary Peruvian plants, food, level and imaginary culture. 


\section{La comida y el comer}

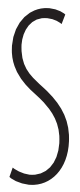

iendo el destino y la función social de las plantas alimenticias alimentar con sus frutos a los hombres, todas se convierten a través de la cocina en comida. La comida, por derivar de las plantas alimenticias que míticamente son de origen divino, involucra también en su naturaleza tal condición: toda comida es de naturaleza sagrada. Desde este punto de vista algunas plantas contienen, inclusive, la inmortalidad, y se harán inmortales quienes las comieran.

El más antiguo monumento literario del mundo, La epopeya de Gilgamesh escrito en lengua sumeria que floreció durante el tercer milenio antes de Cristo, en el extremo sur de la vieja Mesopotamia, nos trajo la noticia. La referencia se la hizo el sagrado Utnapishtim a Gilgamesh, como premio a su proeza de haber llegado al mundo de los muertos, para saber la existencia de la planta que haría retornar a la vida a su amigo Enkidu:

Hay una planta que se oculta en algún punto entre las peñas

que se basta a sí misma y en lo honde se hunde

en la tierra, con cardos que aguijonean.

Aquella planta contiene la vida eterna que buscas.

(Tablilla XI, Columna VI) ${ }^{1}$

Pero en el retorno a Uruk, ciudad de pastores (actual Al Marka), mientras el héroe se bañaba en una ensenada, una serpiente se apoderó de ella, la engulló y rauda se sumergió en las aguas, al mismo tiempo que rejuvenecía. Se perdió la posesión por el hombre de la planta de la inmortalidad. Muchos siglos más tarde, la Biblia situó al árbol de la inmortalidad en el centro del huerto del Edén; era el árbol de la ciencia, del bien y del mal, cuyos frutos le fueron prohibidos comer a la pareja adánica, si lo hacían morirían.

Los frutos de las plantas alimenticias son el resultado de una larga cadena de trabajos que concluyen en la cosecha. De igual manera, la comida es el producto final de otro ciclo de actividades. Vale decir, entonces, que el trabajo humano es la fuerza que hace útiles a las plantas alimenticias.

Míticamente la necesidad de comer es común a dioses y humanos, pero el trabajo es un castigo impuesto por los primeros. Atrahasis, otro poema mesopotámico compuesto a principios del segundo milenio antes de nuestra era, narra que los dioses menores al padecer en el trabajo diario, un día decidieron no trabajar más, que otros seres se ocuparan de cargar las pesadas cestas con las que conducían herramientas, escombros, tierra, piedras y desechos mil. Se quejaron a los dioses mayores; estos acogieron su demanda y para relevarlos de la dura ocupación, decidieron crear al hombre. El mundo sufrió un cambio drástico, mientras los hombres se encargarían de toda suerte de trabajos, los dio-

1 Epopeya de Gilgamesh, traducción de Iván Augusto Pinto Román. Lima, Universidad Ricardo Palma, Instituto de Estudios Clásicos Occidentales y Orientales, 2006, p. 94. 
ses convertidos en seres supremos, no trabajarían más, cada cual instalado en su palacio celestial, sentado en su trono se dedicaría solamente a contemplar por la eternidad la obra que había creado.

Siglos después, la Biblia, ya creado el hombre, sería en este tema y en el de alimentación más contundente. Primero, hubo una descripción del paraíso vegetariano y dentro del orden allí imperante, el alimento vegetal estaría destinado al hombre y el alimento cárnico (el de los sacrificios) a Dios. Pero el código fue más lejos. Por castigo de Jehová, el hombre para comer, trabajaría con dolor todos los días; la tierra maldita produciría para él solo: Espinos y cardos ${ }^{2}$. De este modo:: «el código alimenticio aparece una vez más como el signo, al mismo nivel que el lenguaje o al menos de una manera parecida, mediante el cual se expresa un pueblo, una sociedad, en su relación con el mundo y con el universo entero» ${ }^{3}$

La necesidad de comer hace iguales a dioses y hombres, aunque no de manera total, pues los dioses toman de la comida solo los vapores y aromas. A partir de este modo de alimentarse de los dioses, las religiones establecieron tabúes en relación a la comida y la cocina. Según la Biblia para los dioses se reservarían los alimentos cárnicos en forma de ofrendas y sacrificios y para los hombres estarían destinados los vegetales. Jehová le dijo a Adán, con crueldad: «comerás hierba del campo» (lbíd. Vs. 18).Este código alimenticio triunfaría en el inmenso territorio que abarcaría con el tiempo la Biblia, territorio donde otros pueblos y otras religiones, hacía muchísimo tiempo también habían impuesto leyes de igual naturaleza.

Entre los alimentos hay un signo jerárquico en concordancia con las estructuras sociales. Los frutos de las plantas alimenticias, a lo largo del tiempo, fueron encontrando su lugar dentro de la escala de las jerarquías socioeconómicas. No todas ocuparían el mismo rango; unas serían superiores y con alto prestigio, otras se asimilarían a los espacios medios, y las demás encontrarían su ubicación en los estamentos inferiores o en las zonas periféricas. En cada uno de estos espacios se encontrarían con gentes igualmente agrupadas de acuerdo a su rango económico, social y cultural. Expresado de otro modo, entre los hombres y los alimentos se establecería una espontánea y mutua correspondencia socioeconómica y cultural, de forma tal que los alimentos superiores, medianos y bajos, serían consumidos por hombres de igual categoría dentro de la pirámide social.

Los cereales, luego de ser domesticados y cultivados ocuparían a nivel mundial un lugar preferencial. Serían útiles para la elaboración de la comida, y luego de la bebida. El trigo sería la especie que llegaría a ocupar el lugar más alto y asimismo la que llegó a aureolarse del más encumbrado prestigio cuando el hombre inventó el pan. El pan bíblico, el mismo que Jesús multiplicó junto con los peces, y que en la última cena le sirvió para instituir la eucaristía. A partir de este acontecimiento, en cumplimiento de sus palabras, el pan simbolizaría su cuerpo, símbolo que convirtió al trigo en representante de Jesús y su vida, desde su nacimiento, pasión, muerte y resurrección.

Génesis, Cap. III. Vs. 17, 18, 19.

Châtelet, Noëlle, La aventura de comer, (Editions du Seuil, 1977 et 1998) , 2001 Lluvia Editores, Lima. 


\section{Jerarquía de las plantas alimenticias andinas}

La cultura popular andina expresa de muchas maneras la jerarquía de las plantas alimenticias en concordancia con el rango social. Una de esas formas es la que las canciones de las fiestas comunales o familiares la expresan.

Hace muchos años escuchamos de modo directo una canción con este contenido, en una fiesta matrimonial indígena. Había una multitud de hombres y mujeres, que luego de la misa ceremonial en la iglesia del barrio La Soledad, de la ciudad de Huaraz, retornaba a su estancia por el barrio periférico llamado Quenash, en el lado oriental de la ciudad. La seguía una banda de música de apenas cinco miembros, que tocaba un huayno. La multitud iba bailando y a simple vista se advertía que había bebido licor. Entre los que danzaban había una campesina cuyos cabellos habían empezado a encanecer; quizás era la madre, tía o hermana de uno de los consortes. Al mismo tiempo de bailar cantaba una canción irónica, cuyos versos son los que siguen:

\section{CANCIÓN 1}

$\begin{array}{ll}\text { Stajtsé cholu kuyéniki } & \text { Ahí tienes, cholo, a quien amas, } \\ \text { stajtsé china welliniki, } & \text { ahí tienes, mujer, a quien quieres. } \\ \text { kananka vidata pasanqui } & \text { Ahora van a aprender a vivir la vida } \\ \text { tauri cafeta upurpis } & \text { saboreando aunque sea café de tauri. }\end{array}$

Otra canción es la que aún entonan las pallas de las fiestas campesinas en las que se representa al inca rodeado de sus princesas y de su general Rumiñahui:
CANCIÓN 2
Upianki, mikunki nimamki
Me reprochas que como y bebo feliz
mikunki, upianki nimanki
me dices que como y bebo con gusto
imékatarac, ekekatarac micuman
qué y cuánto podré comer como dices
cuyi, gallinalla mikukoj.
si yo como solo cuy y gallina.

Analicemos brevemente cada una de estas canciones.

La canción 1 superficialmente tiene un discurso irónico y festivo que remite a quien la escucha a la alegría, la risa y la burla. Pero en su interior profundo oculta el padecimiento existencial que concuerda con su entorno físico y social. Primero, desde el punto de vista físico, Quenash ${ }^{4}$ en la época en que fue escuchada la canción-1 era un barrio periférico, pobre, habitado por sastres, zapateros, músicos populares, donde había chicherías y tenduchas que expendían cachivaches; en suma era la orilla de la ciudad habitada por desempleados, vagos y de migrantes campesinos. Su única calle José Olaya, que atravesaba

4 El significado de esta palabra quechua se ha perdido. Una antigua referencia asegura que en esa zona había una plaga de mosquitos chupadores llamados quenash. 
un arroyuelo y pequeños huertos, al final de su última cuadra tenía clavada a la pared de una casa pobre, la cruz del viajero, frente a una peluquería cuya clientela era indígena y gente popular. Allí terminaba Quenash, y lo que seguía se llamaba igual que hoy Auqui, es decir anciano, denominación que se asocia a los apus, con su río caudaloso del mismo nombre. A partir de este lugar se extendía antes de 1970 el campo. Ahora es una zona cubierta por un nuevo barrio surgido después del terremoto del 70, integrado por gente popular de variado nivel entre los que hay comerciantes informales, profesionales, artesanos, etc. Al término de este núcleo, desde las orillas de otro tío, el Paria, aparecen las colinas y llanuras hasta las estribaciones de la Cordillera Blanca de glaciares enhiestos. En este ámbito la dura tierra frutece cuando se la cultiva con esfuerzo. Este amor a la tierra para arrancarle el fruto que da vida, es el mismo que une al hombre y a la mujer hasta la muerte. La multitud que acompañaba a los recién casados y estos mismos iban a su querencia ubicada en ese espacio de las tierra duras, es decir se dirigían al mundo de la pobreza y del trabajo sacrificado.

Segundo, la voz del yo poético que le dice al varón que ahí tiene a la mujer que adora, y a esta que ahí tiene al hombre que ama, exhorta a los dos a una unión eterna que ha de trascender venciendo a la dureza existencial. Aquí, en este instante, relampaguea la verdad, que el amor auténtico tiene que sobreponerse a la amargura del vivir, que el amor es dulce y la realidad de la vida tiene otro sabor. Esto significa que vivir amando requiere de un aprendizaje. El resultado del "aprender a vivir" es la reunión en un solo haz de lo dulce y lo de amargo. Lo dulce y amargo están simbolizados por el tauri (lupinus mutabilis). Para entender este simbolismo no hay que olvidar que esta planta alimenticia es maldita, y su fruto amargo carece de prestigio económico y social. Su fuerte amargor requiere para ser eliminado de un tratamiento laborioso. Este fruto llamado comúnmente chocho liga a quien o a quienes lo consumen con los sectores pobres y marginales. La vinculación que la canción establece entre el tauri y el café grafica de manera contundente que la vida para ser grata y llevadera, necesita de la dulzura. El café, por naturaleza de sabor amargo, para ser una bebida con visos de golosina necesita del azúcar. Cuánto más, entonces, ha de necesitar de mucho azúcar un café de tauri, expresión que se refiere a lo existencial, a la magia poderosa de la voluntad de amar. El café de tauri metaforiza los sinsabores que los hombres padecen para hallar el alimento cotidiano que debe garantizar la sobrevivencia: fruto o pan que son gratos al hogar, a la vida misma que se nutre del padecimiento y de la ternura. En suma, la canción-1 grafica la jerarquía de las plantas alimenticias en concordancia con la jerarquía que los hombres tienen en la escala social. Para ilustrar este tema debemos recordar un relato mítico nacido como consecuencia de la colonización. En la urdimbre de este relato los colonizados y su cultura fueron expulsados a la periferia por constituir un mundo inferior donde la cultura estaba por hacerse. Uno de los elementos de este mundo incivil, donde según el conquistador la cultura no había nacido, es el tauri ${ }^{5}$, planta que se convierte en el símbolo de la exclusión, de la pobreza, de la incultura y la inferioridad.

5 En el sur peruano esta planta es llamada tarwi, vocablo que pertenece al quechua sureño y central del país. 
La canción 2 nos aproxima a los desniveles sociales. Las pallas en su condición de princesas imperiales no deben consumir alimentos baratos de los que se sirve la gente inferior, sino comidas exquisitas y costosas, que dentro de la manera de alimentarse de toda sociedad, manifiestan poder y superioridad. Estas viandas son aquellas en cuya elaboración entran el cuye y la gallina, es decir elementos cárnicos y que por ser tales expresan riqueza, poder y prestigio. Las princesas pregonan, ante una supuesta idea de los otros, según la cual ellas comen y beben en demasía abusando de su calidad de aristócratas, que ellas no"comen" las comidas populares porque estas son ordinarias y pertenecen a las mayorías. Hacen hincapié en que ellas se nutren solamente de viandas finas, elaboradas con ingredientes cuyo costo escapa a la capacidad adquisitiva de los pobres y que están representadas por la carne del cuye y de la gallina. La canción nos pone frente a una sociedad fracturada en dos, el mundo de los ricos y el de los pobres, los dos separados por la riqueza, el poder y el prestigio. Aquí cobra vigencia la frase socorrida y al mismo tiempo discutible: "Dime lo que comes y te diré quién eres".

La manera cómo la canción expresa lo acabado de decir, suena a queja y resentimiento, pues las pallas, muchachas núbiles con el corazón y el alma llenos de sueños y alegría, saben que el lujo de sus ropas y la exquisitez de las viandas de la fiesta no durarán sino pocos días; que fenecido ese tiempo, para seguir sobreviviendo volverán a sus ocupaciones comunes: pastoreo, trabajos domésticos en la casa o choza suyas, o en casa de los ricos. Para comprender este contenido, es necesario aproximarse a todo de significativo que hay en la oralidad de la danza y de la fiesta misma, en la música del arpa, violín y tinya, en las voces finas de las pallas que se acercan al gemido.

\section{Plantas alimenticias con alto prestigio}

El trigo, el maíz, la papa, las habas y arvejas son plantas cuyos frutos tienen alto prestigio. Las tres primeras están vinculadas a las deidades; el trigo a Jesús y la papa y el maíz a los dioses del panteón andino, lo que les aureola de enorme prestigio.

El trigo ocupa la cúspide de la pirámide vegetal, le siguen el maíz, la papa, las habas y arvejas. Sin embargo hay la necesidad de hacer constar que determinadas variedades de trigo y de maíz ocupan un espacio marginal. Por ejemplo, las variedades del trigo, las llamadas wascar y niño fueron por mucho tiempo discriminadas, hasta que desaparecieron por una tácita renuncia a seguir sembrándolas. De la primera variedad solo se alimentaban los campesinos en extrema pobreza, los demás lo sembraban no para alimento sino para utilizar sus tallos que por ser largos servían para el techado de sus chozas o casas rudimentarias. Una escala un poco superior a la variedad wascar ocupaba el trigo niño que fructificaba inclusive en climas fríos, a más de 3000 msnm. Sus granos aunque pequeños con aspecto envejecido y mustio daban una excelente harina; por largo tiempo fue el alimento cotidiano del campesino de las zonas altas de los Andes hasta que la aparición 
de nuevas variedades lo desplazaron definitivamente. En la ciudad, el trigo wascar y niño no eran aceptados; los propietarios de tierras extensas situadas en el valle y las zonas bajas, dedicaban su aprecio a las variedades finas, hoy desaparecidos: el trigo barba negra y barba azul, que daban granos grandes, duros y brillantes, especiales para la elaboración de harina excelente para el pan cotidiano.

Igual cosa sucedía con el maíz. El producto de esta planta en todas sus variedades, en el campo era el alimento cotidiano, en diversas formas, como cancha, mote y harina; además de ser utilizada para la elaboración de la jora que servía para la chicha, bebida hasta hace poco común en el campo y en el sector popular de la ciudad ${ }^{6}$. En la zona urbana no todas las variedades del maíz eran apreciadas por igual, los ricos de estirpe blanca, por lo común terratenientes, comerciantes, profesionales o rentistas utilizaban solamente el maíz blanco: primero, en la época de los choclos preferían únicamente las mazorcas blancas para la preparación de las humitas; luego de las cosechas, para hacer el mote en sus dos formas con cáscara y sin cáscara; con cáscara para acompañar las viandas en las que se usaba la carne del cerdo, en especial cuando se obtenían chicharrones: y el mote sin cáscara (maíz pelado con ceniza) para la elaboración del tamal o de algunas clases de mazamorras, por ejemplo la hecha con calabaza. Otras variedades de maíz muy apreciadas por el mismo sector rico, era el terciopelo y el warotambo que eran utilizadas en cancha que era consumida cotidianamente. A la población popular de la ciudad no le importaba establecer diferencias entre las variedades del maíz, las utilizaba por igual en su alimentación.

Lo expresado sucedía también con las papas. En el área rural nadie hacía distinciones, estas eran practicadas en los sectores minoritarios de la ciudad; los ricos, aquellos que se consideraban de alta estirpe, preferían las papas arenosas y blancas, de textura suave y almidonosa.

Las habas y arvejas eran consumidas solamente en las zonas bajas, donde por el clima abrigado y la buena calidad de las tierras, las cosechas que estas plantas brindan son abundantes, cosa que no sucedía en los lugares de la altura. El espacio urbano era y es un buen consumidor de ellas. Sin embargo en el consumo practicado en el campo y en la ciudad hay diferencias. En el campo, por lo común son consumidos en gran cantidad luego de las cosechas, es decir cuando los frutos están bien secos, en dos formas: como harina para las sopas; o ligeramente tostadas y hervidas hasta su cocción, es decir en shinti. En la ciudad el consumo en forma de shinti caracterizaba y aun caracteriza al grueso de la población, es decir al sector popular; el consumo en forma de harina es por igual en todos los sectores. La mesa cotidiana de la ciudad utiliza muy poco habas y arvejas secas; las usa diariamente cuando son tiernas o verdes, en la preparación de ensaladas sopas y guisos de carnes variadas acompañadas de arroz. El uso de las habas y arvejas secas que caracteriza al ámbito rural es calificado por la ciudad como consumo "ordinario", adjetiva-

6 En la actualidad la chicha está siendo desplazada por la cerveza y otros licores. El campesino de hoy, que no es el de antes de la reforma agraria y del fenómeno de las migraciones, ya no acepta la chicha, sino licores finos. En las zonas donde ha revivido el ritual precolombino del pago a la tierra tampoco se usa ya la chicha sino vino, cerveza y hasta whisky. Estos indicadores manifiestan el cambio rotundo que se está dando en los Andes. 
ción que implícitamente califica el uso de estas legumbres en estado tierno "verde", como "decente" y distinguido. El consumo de habas y arvejas "secas" es una cholería.

\section{Plantas alimenticias con bajo prestigio}

La cebada, el pushpu, la oca, el olluco, la mashua, el tauri y la quinua son plantas alimenticias cuyos frutos tienen bajo prestigio. La cebada era y es usada solo en la alimentación del cerdo, cuando este debe ser cebado para la obtención de la manteca, jamones y cecina que son carnes apreciadas. Comer cebada evidenciaba una aguda pobreza y esto sucedía en el pasado siglo en muchas familias campesinas. Por lo común la gente pobre acostumbraba tostarla y reducirla a harina ligeramente áspera, llamada machka que servía para acompañar el consumo de una sopa elaborada también de harina de cebada sin tostar o para el desayuno que consistía en una infusión de alguna planta aromática o café de cebada tostada hasta ser negra. En el caso de la machka la harina era cernida para la eliminación de la cáscara.

Lo mismo sucedía con el pushpu ${ }^{7}$ o frejol andino, que era alimento campesino cuando estaba seco. En la ciudad no era estimado, inclusive el sector popular no lo aceptaba; en la escuela era común el insulto de pushpu lagua (sopa) que servía para nombrar a los estudiantes pobres que supuestamente se alimentaban solamente de una sopa de harina de pushpu. Igualmente la mashua era la comida de quienes vivían en la pobreza extrema tanto en el campo como en la ciudad. El campesino rico cuyas cosechas de maíz, papa, trigo, eran abundantes, se jactaba de no comerla. Si la sembraba era solo por costumbre, en forma sumamente reducida, en los últimos surcos de una chacra de papas, ollucos u ocas. El tauri enfrentaba igual suerte, su cultivo era reducido y pocos campesinos lo practicaban, a tal punto que en una plantación de papas, en uno de los bordes había por lo común, uno o dos surcos de tauri. La cosecha era abundante, sus granos luego de hervidos durante varias horas para la eliminación de su amargor, eran depositados en costalillos que tenían que permanecer dentro del agua corriente por varios días; solo así era consumido en guiso con ají y papas o en ensaladas. Era una idea generalizada que la mujer que bebía el agua en la que había hervido el tauri evitaba el embarazo. No otra suerte enfrentaba también la quinua, que por mucho tiempo ha sido comida únicamente del campesino. El habitante de la ciudad le dedicaba poca estimación. ${ }^{8}$

$7 \quad$ Frejol andino de distintos colores; los había muy hermosos que por sus colores en la escuela eran llamados "lecheras" en el juego de bolas; había lecheras rojas, con manchas blancas, o negras con manchas iguales. También había los negritos que en la punta tenían una mancha blanca en forma de media luna, eran los llamados lengüitas. La incuria y el desprecio de la ciudad y de los campesinos que han migrado a la costa o a las ciudades ha precipitado su desaparición.

8 En la actualidad se advierte un cambio drástico en cuanto se refiere a la importancia de muchas plantas alimenticias nativas. Si antes la quinua, la mashua, el tauri fueron relegados, ahora hay un retorno a ellos. En las calles de las ciudades y pueblos del interior del país se expende ensalada de tauri que la gente y los turistas consumen felices por sus cualidades altamente nutritivas. Hay una comida llamada "ceviche andino", cuyos ingredientes son tauri, trucha 


\section{Dime lo que comes, te diré quién eres}

En la fiesta de los carnavales, en décadas pasadas, se cantaba y aún se canta en la actualidad en contados pueblos, una canción que tiene los siguientes versos:

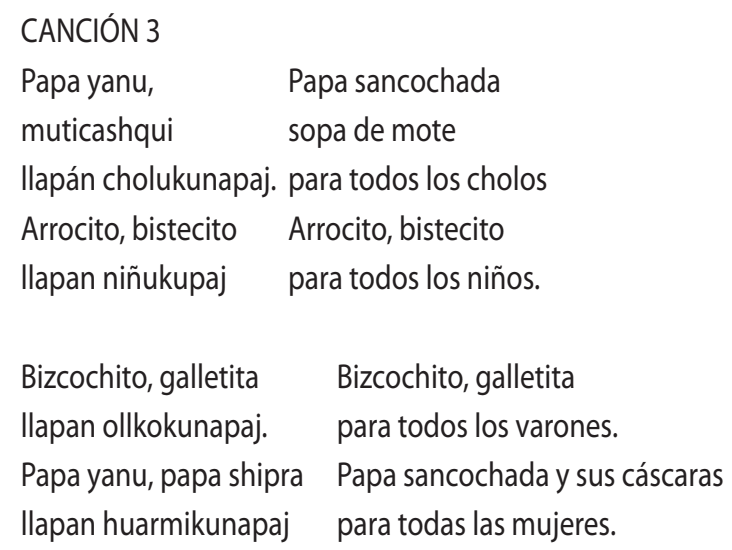

Esta canción (huayno) de música suave y afiligrinada expresa los desniveles y desajustes sociales. El mundo aparece fracturado en dos ámbitos, cada uno con sectores que enfrentan una asimetría: 1) El de los cholos y el de los niños ${ }^{9}$, 2)el de los varones y mujeres.

En el primer ámbito aparecen: a) los cholos con sus múltiples gradaciones sociales, desde el campesino e indio letrado hasta los mestizos pobres de la ciudad, todos étnicamente no blancos, b) los niños que representan a los ricos, habitantes de la ciudad, étnicamente blancos y con una buena posición social, muchos de ellos terratenientes o hacendados. Cada uno de estos sectores están sustentados por sus alimentos correspondientes; los cholos, por ser inferiores, se alimentan de comidas ordinarias, poco costosas, elaboradas con productos alimenticios de baja calidad; $y$, los niños por ser superiores se sustentan de viandas exquisitas cuyos componentes son alimentos de alto prestigio. En uno y otro caso, la calidad de la comida pone al descubierto la pobreza y la riqueza como factores que estratifican a los integrantes de la sociedad.

En el segundo ámbito se encuentran: a) los varones, b) las mujeres, no en iguales condiciones, sino dentro de una realidad donde campea la desigualdad. Los varones ocupan una posición superior y las mujeres una inferior. La comunidad a la que pertenece la canción es machista. Los varones se alimentan de cosas finas (bizcochito, galletita), las mujeres están obligadas a comer cosas no solo ordinarias, sino hasta degradantes, las cáscaras de las papas, que las acercan a los desechos o a la basura. Esta desigualdad en-

frita, cancha de maíz, ají, cebolla y hierbas aromáticas. Por último la quinua embolsada se expende en los grandes mercados de los barrios residenciales de Lima, cuyos habitantes la consumen incentivados por sus características nutritivas y debido a los precios altos de la carne.

Gente blanca, habitante de la ciudad, económica, social y culturalmente desarrollada. 
tre el varón y la mujer cubre por entero a la población rural y urbana y funciona también dentro de la sociedad rica.

El consumo de alimentos en un nivel comparativo, especialmente en la población urbana originó dos estilos, ayer más acentuados que hoy: a) el "estilo decente", b) el "estilo plebeyo" dentro del cual están involucrados el popular, el pobre e indio. Estos dos estilos dentro de un contexto mayor reproducen los estratos sociales y económicos de los hombres, y tienen asimismo connotaciones culturales, sociales y raciales.

La antropología de las comidas y de la alimentación es un campo sumamente extenso que hoy es abordado con entusiasmo. Se tiende a superar la orientación funcionalista que ha primado en el estudio de la comida. Hoy se procura destacar sus significados construidos dentro de la sociedad. Esta perspectiva nos mueve a añadir algunas líneas a las ya escritas a propósito de las canciones 1 y 2. Es inevitable saber lo que se come, cómo se come, el valor de lo que se come, la metaforización y simbolización de la comida.

Un mismo producto alimentario puede originar una variedad de comidas y modos de comer y cada de estos revela diferentes estatus económicos, sociales, culturales, etc. Tomemos un ejemplo, la papa. Este producto puede ser consumido de diversa manera: 1) sancochada, 2) en puré, 3) en causa, 4) a la huancaína, 5) frita, 6) pastel, 7) papa rellena, etc. La primera forma es la de la pobreza que corresponde a los sectores económica, social y culturalmente deprimidos, en tanto que las siguientes a los estratos sociales que además de tener excelente capacidad económica disfrutan de una cultura que les induce a adoptar estilos civilizados que tienden a sofistificarse. Comer, es pues, no solo la manera de satisfacer el hambre y de nutrir el cuerpo, sino es un acto en el cual y a través del cual el hombre, la sociedad, encuentran una manera de exteriorizar sus recursos materiales, psicológicos, culturales, etc. No es igual comer papas solo sancochadas y un plato de papas rellenas o fritas con la carne de pollo a la brasa. La comida y el comer asumen caracteres significativos en tanto se relacionan con las fiestas familiares o sociales, ceremonias de duelo o de rituales religiosos, etc. Comer es una aventura y en este acto también hay fantasía y voluptuosidades, expresa Noëlle Châtelet. Hay mucha verdad en esto. En el capítulo: "Las voluptuosidades de la boca y del amor", de su libro. La aventura de comer, escrito al parecer inspirado por un pensamiento del marqués de Sade: «No hay ninguna razón para que una fantasía de mesa nos parezca menos extraordinaria que una fantasía de cama», hay bastante información. ${ }^{10}$

Fuera de los contextos mencionados hay un espacio amplio donde el impacto de la extrema pobreza es demasiado fuerte, y que determina una forma de alimentación absolutamente deficiente, que en palabras del sociólogo brasileño Josué de Castro ${ }^{11}$

10 Páginas 149-169.

11 Josué de Castro fue escritor y profesor universitario que por muchos años presidió la FAO, organismo de las Naciones Unidas especializado en los problemas de la agricultura y la alimentación. Escribió: El libronegro del hambre, Geopolítica del hambre, Biología social y geografía humana, que en la década de 1950 y 60 tuvieron una extraordinaria difusión y fueron traducidos a varios idiomas. Josué de Castro acuñó el pensamiento de que el tema del hambre es un tabú, como el del sexo. Por ser tabú, nadie quiere hablar del hambre. 
determina lo que él llamó el hambre crónica y que por esta característica no encaja ni siquiera dentro del estilo de comer plebeyo. En este espacio se encuentra aún una gruesa población rural y urbana marginal y desamparada, en la que hay consumidores de comidas de calidad extremadamente inferior. Tenemos los comedores de la sopa karpí, elaborada sin manteca o aceite, sino únicamente con harina hervida en agua con sal, costumbre del campesino con ningún poder económico, que no posee cerdos y si los tiene son animales esqueléticos, a los que no puede cebar por carecer de cebada o maíz, circunstancia que explica la carencia de la manteca para la preparación del "ahogado" (mezcla de manteca, cebolla, sal, ají) que da sabor a toda comida. Igual a los comedores de la sopa karpí son los consumidores de variedades de hojas de plantas o yuyos, tales como el atakosh, ñabuy pató (mastuerzo silvestre). El atakosh y pató, llamados yuyos o jitka, crecen en los maizales, y el ñabu en los trigales. A este conjunto de yuyos se agregan las hojas del olluco, a las que se les llama lutu, que se consume hervidas; y también las hojas tiernas de la quinua que se cuecen en las sopas de harina. En extensas zonas de las punas, entre Ancash y Huánuco, los pastores elaboran una sopa con diversos yuyos que son hervidos y cocidos en agua con sal, sin ningún ingrediente más, es la comida llamada santucaldo o caldo santo.

Hoy en día estamos asistiendo a cambios cada vez más agudos. Antes, muchos productos de las plantas alimenticias andinas eran rechazados en la ciudad, sea esta andina o costeña y con mayor énfasis en Lima, donde, por ejemplo, eran rechazadas las papas de color que eran consideradas ordinarias. Ahora los grandes centros de expendio de alimentos venden en gran cantidad frutos andinos: olluco, mashua, quinua, habas, papas de todo color, etc. Esto significa un fenómeno de cambios que se han operado y continúan dándose en el nuevo orden nacional cada día más andinizado. Por último es necesario expresar que el mundo de los productos alimenticios, de las comidas y del comer es muy, pero muy extenso, profundo y complejo. Merece extensivos y agudos estudios desde un ángulo de una visión multidisciplinaria, interdisciplinaria y transdisciplinaria.

\section{Referencias bibliográficas}

BRANDES, Stanley (1988). «La comida ceremonial en Tzintzuntzan». América indígena. Instituto Indigenista Interamericano. № 3, México, D.F. pp. 503-520.

ChÂTELET, Noëlle ([1977, París] 2001). La aventura de comer. Lluvia Editores, Lima.

GARINE, Igor de (1988). «Antropología de la alimentación y pluridisciplinariedad». América indígena. Instituto Indigenista Interamericano. № 3 México, D.F. pp 635-648.

Ossı, Juan M. (1988). "Aspectos simbólicos de las comidas”, América indígena. Instituto Indigenista Interamericano, № 3, México, D.F.

VAn KesSEL, Juan, CONDORI CRUZ, Dionisio (1992). Criar la vida. Trabajo y tecnología en el mundo andino. Santiago de Chile.

VARIOS (1999). Las crianzas de las wacas. PRATEC. Proyecto Andino de Tecnologías Campesinas. Lima. 
YAURI MonTeRO, M. (1979). Leyendas ancashinas. P.L. Villanueva Editor. Lima.

YAURI M. (1993). El Señor de la Soledad de Huarás. Discurso de la abundancia y carencia. Resistencia andina. Editorial AVE S.A. Lima. 